\title{
EXPERIMENTAL INVESTIGATION ON DRYING OF BLANCHED BITTER GOURD SLICES IN A TRIPLE PASS SOLAR DRYER
}

\author{
S.Kesavan ${ }^{a^{*}}$, T.V. Arjunan ${ }^{1, b}$, S.Vijayan ${ }^{2, b}$ \\ ${ }^{a}$ Department of Mechanical Engineering, DDCSM Polytechnic College, Palacode, \\ Dharmapuri District, Tamil Nadu. India. \\ sk7mch@gmail.com \\ ${ }^{b}$ Department of Mechanical Engineering, Coimbatore Institution of Engineering and Technology, Coimbatore, \\ Tamil Nadu, India. \\ 1'arjun_nivi@yahoo.com, 2'vjnsel@gmail.com
}

\section{ABSTRACT}

This paper involves with the experimental performance study of a triple pass solar flat plate collector integrated with thermal energy storage medium for drying of blanched bitter gourd slices. The experimental setup consists of a blower, triple pass flat plate collector and a drying chamber. The experimets were carried out in the meterological conditions of Coimbatore, Tamil Nadu, India. The mass flow rate of air through the system was set as $0.06 \mathrm{kgs}^{-1}$. From the results, it could be comprehended that, (i) triple pass arrangement of air improves the performance of flat plate collector (ii) thermal energy storage medium played an important role in consistent outlet air temperature and the thermal efficiency (iii) triple pass solar dryer took 5 hours to reach the final moisture content of bitter gourd ( $9 \%$ on wet basis) which is $29 \%$ and $37.5 \%$ faster than without thermal storage and open sun drying system. It could be concluded that triple pass solar air collector performs better than without thermal storage and open sun drying.

\section{Keywords}

Triple pass, solar dryer, wire mesh, thermal energy storage, bitter gourd

\section{INTRODUCTION}

Solar drying is the most popular method for removing the moisture content from the agricultural products. It helps to: reduce the post harvest losses; increase the self-life of the product; prevent the spoilage of the product; safe storage; products available throughout the year; easy transportation due to less weight. The main hurdles faced with the solar dryer are less thermal efficiency, availability of the system for drying etc., Different solar dryers with performance improving techniques like to incorporate thermal storage medium, heat transfer enhancing elements, etc., for drying agricultural products are enlarged by the plethora of researchers.

Jain and Jain [1] studied the performance of the inclined multi pass solar air heater with inbuilt thermal storage on deep-bed for drying application. From the study, they observed that drying rate depends on the depth of drying bed and the moisture content also decreases with the time. Jain [2] explored the performance of inclined multi-pass solar air heater with inbuilt thermal storage for drying of the paddy crop. To find the drying rate and reduction of moisture content in the trays Jain has used thin layer drying equation. The results of the study pictures that crop moisture content decreases with the drying time and the drying rate varies with tray arrangements. Mittal and Varshney [3] investigated on a solar air heater packed with blackened wire screen matrices of different geometrical parameters. They found packed bed solar air heater was thermo hydraulically efficient when compared to flat plate collectors. El-Sebaii et al. [4] augmented and evaluated a double pass solar collector with iron packed bed. From it, they observed that the efficiency of the system was $22-27 \%$ higher than the system without packing bed. Prasad et al [5] experimented the heat transfer and friction characteristics of packed bed solar air heater using wire mesh as packing material. Low value of porosity gives better performance is the conclusion given by them after the study. In addition to it, they showed that the heat transfer coefficient increases with a decrease in porosity. Aldabbagh et al [6] analyzed the performance of the single and double pass solar heaters with wire mesh as packed bed. From the analysis, it is understood that double pass solar air heater achieved a higher efficiency $(83.65 \%)$ than single pass solar air heater $(45.93 \%)$.

Omojaro and Aldabbagh [7] studied the performance of single and double pass solar air heaters with wire mesh as packed bed and concluded that the efficiency of the double pass was higher than the single pass. Banout et al. [8] studied the performances of Double-pass solar dryer (DPSD). For the study, they compared DPSD with a typical cabinet dryer (CD) and a traditional open-air sun drying for drying red chili. The overall drying efficiencies of DSPD and CD were $24.04 \%$ and $11.52 \%$ respectively to reach the desired moisture content of $10 \%$ (wet basis). This study concluded that DPSD was best suitable than CD for drying of red chili. Banout et al. [9] investigated performance of double-pass solar dryer for jerky drying. In this study, it was found that higher drying rate was achieved in double pass solar dryer than laboratory oven method. Krishnananth and Kalidasa Murugavel [10] investigated the performance of double pass solar air heater with paraffin wax as a thermal storage medium for different configurations. The results indicated that the efficiency of the air heater with thermal storage was higher than without thermal storage and maintained comparatively high temperature air throughout the day. From the literature survey it is noticed that the multiple pass with thermal storage medium exhibits comparatively higher thermal efficiency. In this experimental study a novel triple pass solar flat collector integrated with sensible thermal storage medium. 
The main objectives of this investigation are, (i) to study the effect of triple pass air through the solar collector on its performance and drying characteristics of blanched bitter gourds, (ii) to study the effect of thermal energy storage medium on the collector outlet temperature.

\section{Material and methods}

\subsection{Triple pass solar flat plate collector}

The schematic diagram and pictorial view of experimental setup are depicted in fig. 1 and fig. 2 respectively. It consists of a blower, a triple pass solar flat plate collector and a drying chamber. The dimension of the collector is $2 \mathrm{~m} \times 1$ $\mathrm{m} \times 0.1 \mathrm{~m}$. It consists of two glasses, black painted aluminum mesh and an absorber plate integrated with sensible thermal storage medium Top of the collector was provided with a $4 \mathrm{~mm}$ thick normal window glass to reduce the top loss. The second glass with the same thickness is kept at a distance of $20 \mathrm{~mm}$ from glass 1 to form passage for first pass. Black painted aluminum mesh with dimension of $1.95 \mathrm{~m} \times 0.95 \mathrm{~m} \times 0.025 \mathrm{~m}$ was placed between second glass and the absorber plate. This is to improve the heat transfer rate of air by creating turbulence motion. A flat rectangular box with dimensions of $2 \mathrm{~m} \times 1 \mathrm{~m} \times 0.02 \mathrm{~m}$ made of G.I [Galvanized iron] sheet was used as absorber plate. River sand was filled as thermal energy storage medium to store excess thermal energy during peak sunshine hours. A bottom plate was provided below the absorber with an air gap of $20 \mathrm{~mm}$. The air flows between two glasses during first pass, then flows in the opposite direction between second glass and top surface of the absorber. Finally, it flows through the spaces between the bottom side of the absorber and bottom plate into drying chamber. The air flow directions through collector are clearly shown in fig.3.

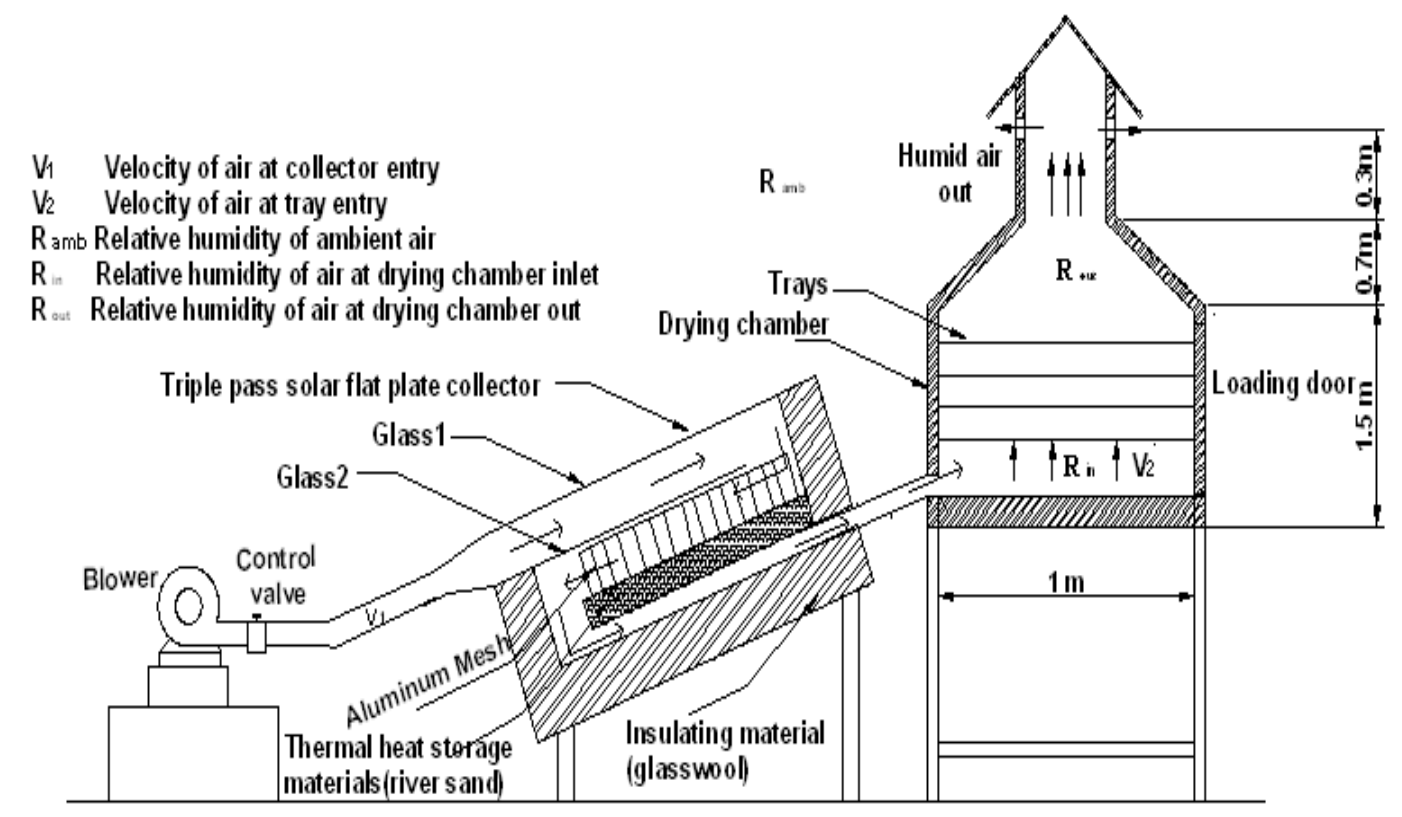

Fig. 1 - Schematic diagram of the experimental setup

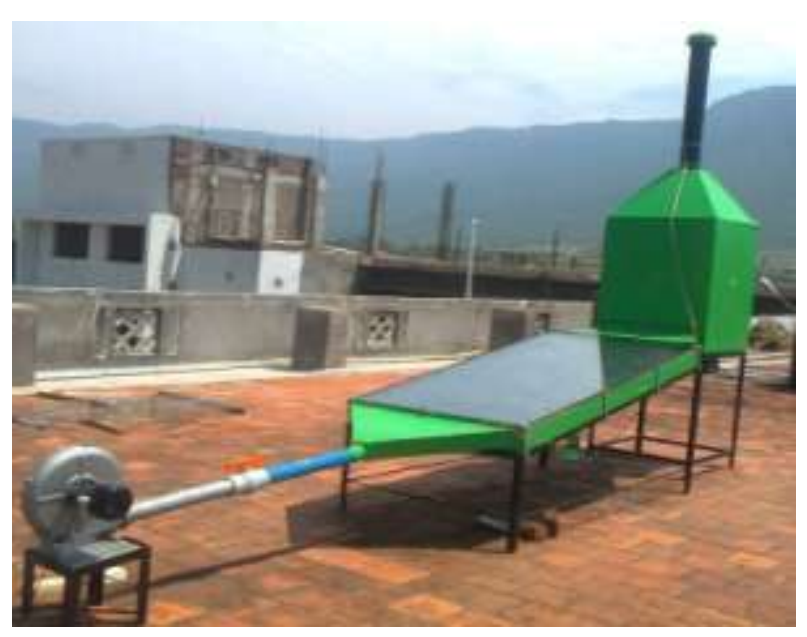

Fig. 2 - Pictorial view of the experimental setup 


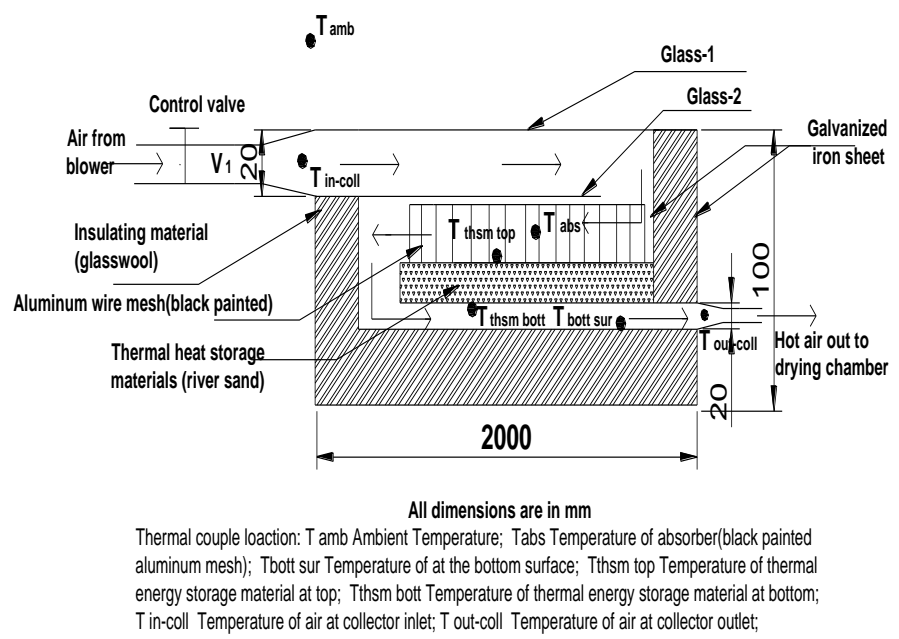

\section{Fig. 3 - Air flow directions through Triple Pass Solar Flat Plate Collector (TPSFPC)}

The collector was connected to a drying chamber of $1.05 \mathrm{~m} \times 1.05 \mathrm{~m} \times 1.2 \mathrm{~m}$. The solar falt plate collector and drying chamber were insulated on all sides using glass wool as insulation material with thickness of $25 \mathrm{~mm}$, to reduce the convection heat losses. A centrifugal blower $(0.75 \mathrm{KW})$ was connected to one end of the collector and the other end with a drying chamber. The angle of the collector was set as $11^{\circ}$ with horizontal position facing south direction to receive the maximum solar radiation. The solar radiation was measured by solar power meter. The detailed specifications of the instruments used in the experimental study are listed in Table 1.

\section{Table 1: Specifications of Instruments}

\begin{tabular}{|c|c|c|c|c|c|}
\hline Description & Make & Model & Range & Resolution & Accuracy \\
\hline Solar Power meter & TES Instrument & TES -1333 & $2000 \mathrm{~W} / \mathrm{m}^{2}$ & $1 \mathrm{~W} / \mathrm{m}^{2}$ & $\pm 10 \mathrm{~W} / \mathrm{m}^{2}$ \\
\hline $\begin{array}{c}\text { Digital Temperature } \\
\text { \& Humidity Meter }\end{array}$ & METRAVI & HT-3006 & $\begin{array}{c}0 \text { to } 100 \% \mathrm{RH} \\
-30 \text { to } 100^{\circ} \mathrm{C}\end{array}$ & $\begin{array}{c}0.01 \% \\
0.01^{\circ} \mathrm{C}\end{array}$ & $\begin{array}{c} \pm \% \mathrm{RH} \\
0.5^{\circ} \mathrm{C}\end{array}$ \\
\hline Anemometer & Kusam-meco & KM-909 & $\begin{array}{c}0^{\circ} \mathrm{C} \text { to } 50^{\circ} \mathrm{C}, \\
0-30 \mathrm{~m} / \mathrm{s}\end{array}$ & $\begin{array}{c}0.1^{\circ} \mathrm{C} \\
0.01 \mathrm{~m} / \mathrm{s}\end{array}$ & $\begin{array}{c} \pm 0.5^{\circ} \mathrm{C} \text { on } \\
0^{\circ} \mathrm{Co} 45^{\circ} \mathrm{C}, \\
\pm 3 \%\end{array}$ \\
\hline Weighing machine & $\begin{array}{c}\text { Accurate } \\
\text { Electronics }\end{array}$ & $\begin{array}{c}\text { ATC-10 W- } \\
\text { Rear }\end{array}$ & 0 to $10 \mathrm{~kg}$ & $1 \mathrm{~g}$ & $\pm 1 \mathrm{~g}$ \\
\hline
\end{tabular}

\subsection{Experimental procedure}

Fresh bitter gourd was obtained from a local market in Coimbatore, Tamil Nadu, India. Before the experimental study, the foreign materials, spoiled and discoloured bitter gourds were removed and to ensure the quality of dried product. Bitter gourd slices were prepared with $5 \mathrm{~mm}$ thick and 41 to $54 \mathrm{mmm}$ diameter by using vegetable slicer. The bitter gourd slices were blanched in hot water $\left(96^{\circ} \mathrm{C}\right)$ for 5 minutes. Then, it was soaked in cold water immediately to avoid the overheating [11]. The initial moisture content of the bitter gourd was determined according to the oven drying method [12] as $91 \%$ (wet basis). For each experimental study about $1.5 \mathrm{~kg}$ of the bitter gourd slices were taken.

The drying experiments were conducted on $10^{\text {th }}$ and $14^{\text {th }}$ of March 2016 between 8.00 am to 5.00 pm under three configurations (Triple pass solar flat plate collector with thermal storage, without thermal storage and open sun). The mass flow rate of air through the system was set as $0.06 \mathrm{kgs}^{-1}$. The solar drying system was operated under no load condition for one hour from 8.00 am to 9.00 am to bring the system to steady state. The weight of the product was measured using an electronic weighing maching in each one hour interval. Solar radiation, air velocity, relative humidity of the air and temperature of different elements of the drying system were also observed.

\subsection{Data analysis}

The performance of the drying system and the characteristics were calculated as follows. The moisture content $\left(\mathrm{M}_{\mathrm{wb}}\right)$ on a wet basis [13] was calculated by Eq. (1), 


$$
M_{w b}=\left[\frac{W_{i}-W_{f}}{W_{i}}\right] \times 100
$$

Where $w_{i}$ - Initial mass of sample in $(\mathrm{kg}), w_{f}$ - final mass of sample $(\mathrm{kg})$

Collector efficiency [ $\eta$ can be expressed [14] as Eq. (2),

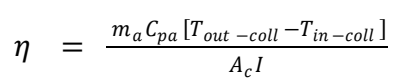

Where, $\mathrm{m}_{\mathrm{a}}$ - mass flow rate of air, $\mathrm{kgs}^{-1}, \mathrm{C}_{\mathrm{pa}}$ - Specific heat, $\mathrm{Jkg}^{-1} \mathrm{~K}^{-1}$,

$\mathrm{T}_{\text {in-coll }}$ - Temperature of air at collector inlet, ${ }^{\circ} \mathrm{C}, \mathrm{T}_{\text {out- coll- }}$ Temperature of air at collector outlet, ${ }^{\circ} \mathrm{C}, \mathrm{A}_{\mathrm{c}}-\mathrm{Collector}$ area, $\mathrm{m}^{2}$, I - Solar radiation intensity on the collector surface, $\mathrm{Wm}^{-2}$ content;

The quantity of water $(\mathrm{W})$, to be removed from wet product is calculated from the initial and desired final moisture

$$
W=\frac{\left(M_{i}-M_{f}\right)}{\left(100-M_{f}\right)} \times W_{o}
$$

The thermal efficiency of the dryer is defined as the ratio of energy required for evaporation to the toral amount of energy supplied to the drying system [15]. It can be found using the following equation (4)

$$
\eta=\frac{W L}{A_{C} I+P_{f}}
$$

The specific moisture extraction rate (SMER) is another important parameter used to evaluate the performance of a drying system [15], which is given as

$$
\text { SMER }=\frac{\text { Total mass of water removed in } \mathrm{kg}}{\text { Total Energy supplied }}
$$
rate [15]

The specific energy consumption (SEC) of the solar drying system is the reciprocal of specific moisture extraction

$$
S E C=\frac{\text { Total Energy supplied }}{\text { mass of water removed in } \mathrm{kg}}
$$

\section{Results and Discussion}

The hourly variation of solar intensity for the days on $10^{\text {th }}$ and $14^{\text {th }}$ March 2016 was shown in fig. 4 and the average solar intensity for the days were $709 \mathrm{w} / \mathrm{m}^{2}$ and $726 \mathrm{w} / \mathrm{m}^{2}$ respectively. Both days were having similar solar intensity profile.

The variation of temperature of air at collector inlet and outlet on the day of study is brought out in fig. 5. The temperature of air at the collector inlet was observed between $33^{\circ} \mathrm{C}$ and $35^{\circ} \mathrm{C}$ and it depends on the atmospheric condition. The figure shows that the collector outlet temperature increases with increase of solar intensity till it reaches its maximum value of $58^{\circ} \mathrm{C}$ at 13 hours. The outlet temperature of the collector with thermal storage medium reaches the maximum value of $55^{\circ} \mathrm{C}$ and during the forenoon the temperature value is lower than the temperature of collector without thermal storage medium, due to the reason of energy absorption by the enery storage and during the off sunshine hours the absorbed energy released slowly to maintain a consistent temperature as mentinoned by Mohanraj and Chandrasekar [13]. Thermal energy storage releases the stored energy during noon hours and supply to the air continuously irrespective of solar intensity. The aluminium wire mesh creates the turbulence in the flow field at the absorber surface. This combined effect of aluminium wire mesh and thermal energy storage medium gets uniform and consistent temperature at the outlet of the collector. These statements are confirmed by referring fig. 5 , which vividly portrays that the outlet temperature of the collector is consistent during 12 to 17 hours irrespective of solar intensity.

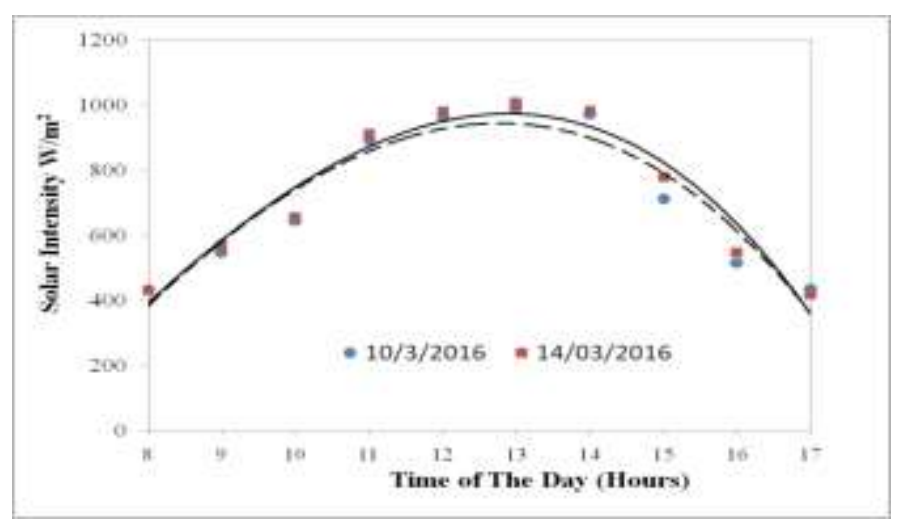

Fig. 4 - Variation of solar intensity on hours of the day

6372 | P a g e 


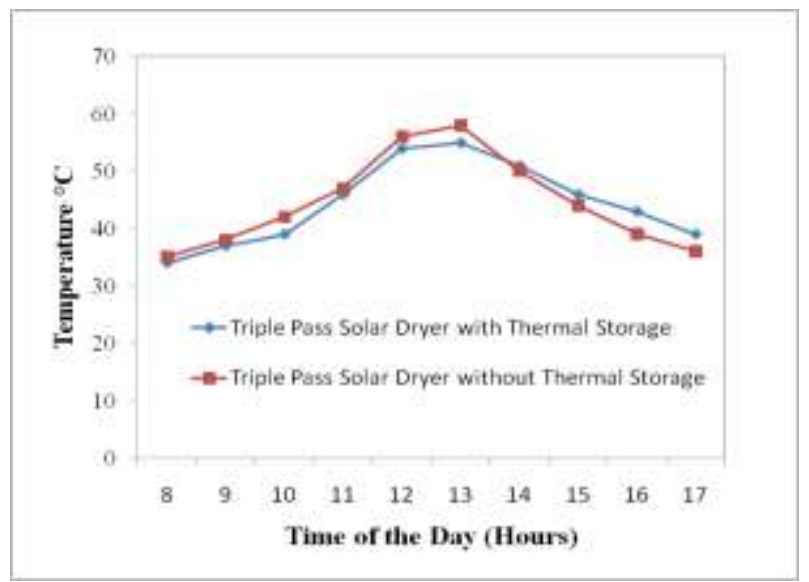

Fig. 5 - Temperature variation of the collector air inlet and outlet

The hourly variation of the instantaneous thermal efficiency of the collector for the triple pass solar dryer with and without thermal storage is shown in fig.6. The thermal efficiency of the collector without thermal energy storage is slightly higher than the efficiency of the collector with thermal storage during the forenoon period but in afternoon period the efficiency of the system is drastically reduced due to reduction in solar intensity. The thermal efficiency of the collector with thermal energy storage exhibiting consistent efficiency in the afternoon or low solar radiation period by releasing the absorbed thermal energy to the flowing air. The average collector efficiencies of the collector without and with thermal energy storage are $32.02 \%$ and $37.21 \%$ respectively.

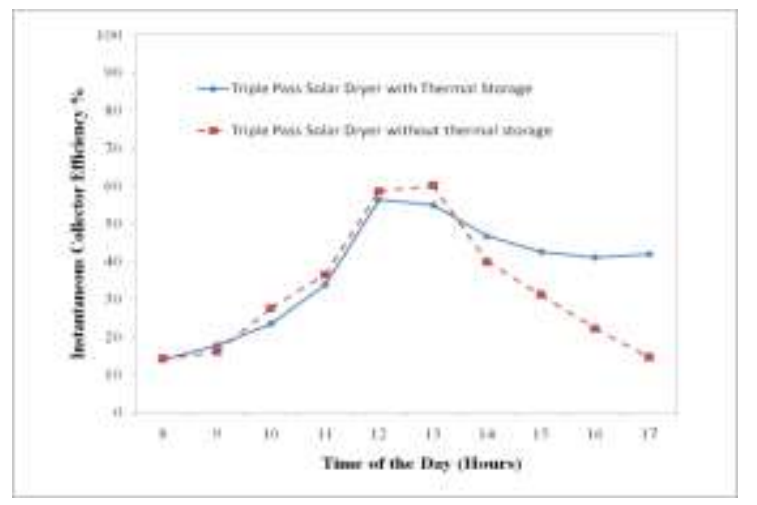

Fig. 6 - Variation of collector efficiency on hours of the day

The relative humidity of air at the collector outlet was obtained in the range of $22 \%$ to $36 \%$. Fig. 7 expresses the relative humidity of air at the inlet and outlet of drying chamber against time of the day. It was observed that relative humidity of the air at drier exit was higher during the initial stages of drying. It decreased with drying time as drying proceeds and became constant in the final stage of drying. The Maximum relative humidity of about $80 \%$ was observed during the initial stages of drying and was gradually reduced to about $50 \%$ at the end of drying. The higher drying rate of the bitter gourd during initial stage of drying, resulting in the release of more moisture in the drying air is the reason. The effect of air temperature at the dryer inlet was also affecting the humidity of air at dryer outlet.

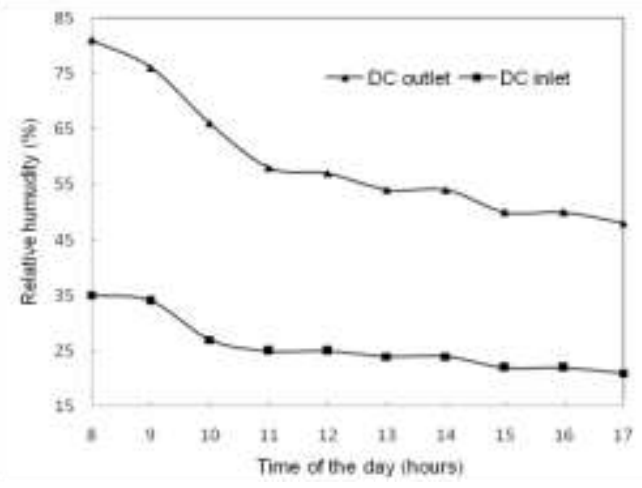

Fig. 7 - Relative humidity of air at inlet and outlet of Drying Chamber [DC] against time of the day 
Fig. 8 depicts the variation of moisture content with drying time for the solar flat plate collector, without thermal storage and open sun drying. The figure clearly shows that TPSFPC, without thermal storage and open sun drying takes 5 hours, 7 hours and 8 hours to reach final moisture content of $9 \%$ from initial moisture content $91 \%$ respectively. The drying performance of TPSFPC drying system gives $29 \%$ and $37.5 \%$ faster than without thermal storage and open sun drying system respectively.

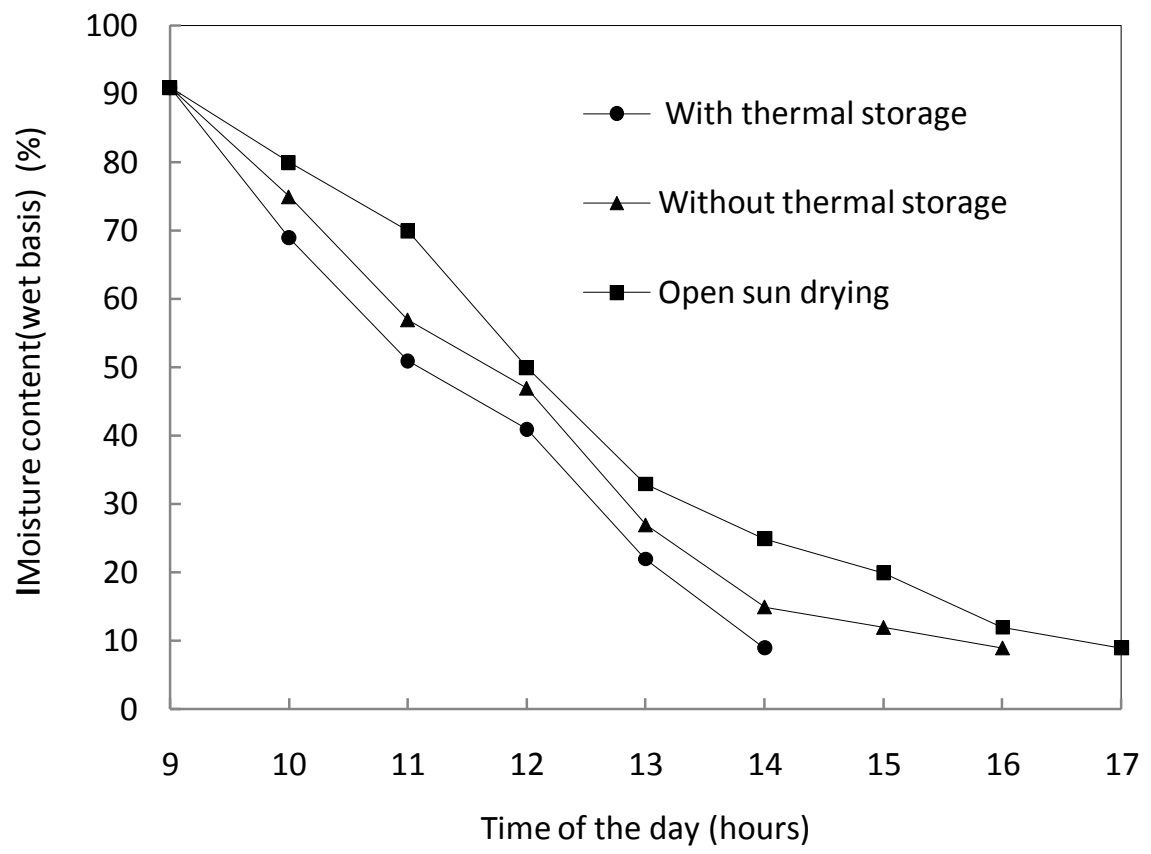

Fig. 8 - Variation of moisture content with drying time

The specific moisture extraction rate (SMER) of the triple pass solar flat plate collector with and without thermal storage medium for drying blanched bitter gourd slices were $0.1341 \mathrm{~kg} / \mathrm{kWh}$ and $0.0957 \mathrm{~kg} / \mathrm{kWh}$ respectively. The specific energy consumption (SEC) were $7.457 \mathrm{kWh} / \mathrm{kg}$ and $10.248 \mathrm{kWh} / \mathrm{kg}$ for the system with and without thermal storage. The result shows that the solar flat plate collector with thermal storage has the higher SMER and lower SEC. The average dryer efficiency of the system with and without thermal storage medium were $32.12 \%$ and $23.37 \%$.

\section{Conclusion}

The performance of triple pass solar flat plate collector integrated with thermal energy storage medium was fabricated and investigated for bitter gourd drying. The triple pass solar flat plate collector with thermal drying system takes 5 hours to reach final moisture content of $9 \%$ (wet basis) for bitter gourd slices which is $29 \%$ and $37.5 \%$ faster than without thermal storage and open sun drying system. The average instantaneous thermal efficiency of the system with thermal storage medium was $37.21 \%$ which is $16.22 \%$ higher than the system without thermal storage medium. It is concluded that the triple pass solar flat collector with thermal storage medium extends the availability of the system about 2 hours and improves the performance of the solar drying system.

\section{Nomenclature}

$\begin{array}{ll}\mathrm{A}_{\mathrm{c}} & \text { Collector area, }\left[\mathrm{m}^{2}\right] \\ \mathrm{C}_{\mathrm{pa}} & \text { Specific heat of air, }\left[\mathrm{Jkg}^{-1} \mathrm{~K}^{-1}\right] \\ \mathrm{I} & \text { Solar radiation intensity on the collector surface, }\left[\mathrm{Wm}^{-2}\right] \\ \mathrm{m}_{\mathrm{a}} & \text { Mass flow rate of air, }\left[\mathrm{kgs}^{-1}\right] \\ \mathrm{M}_{\mathrm{wb}} & \text { Moisture content on wet basis, }\left[\mathrm{kg} \mathrm{kg}^{-1}\right] \\ \mathrm{RH}_{\text {ambient }} & \text { Relative humidity of ambient air, [\%] } \\ \mathrm{RH}_{\text {out-coll }} & \text { Relative humidity of air at collector outlet, [\% ] } \\ \mathrm{T}_{\text {in-coll }} & \text { Temperature of air at collector inlet, }\left[{ }^{\circ} \mathrm{C}\right] \\ \mathrm{T}_{\text {out-coll }} & \text { Temperature of air at collector outlet, }\left[{ }^{\circ} \mathrm{C}\right] \\ \mathrm{T}_{\text {abs }} & \text { Temperature of absorber (black painted aluminum mesh), }\left[{ }^{\circ} \mathrm{C}\right]\end{array}$




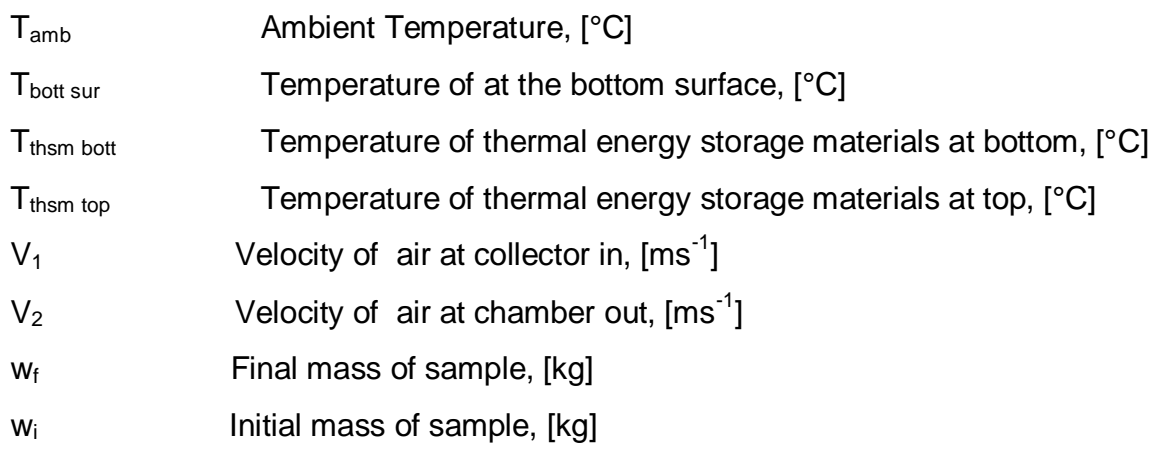

Greek symbols

$\eta \quad$ Collector efficiency, [\%]

\section{References}

1. Jain Dilip., Jain Rajeev Kumar., Performance evaluation of an inclined multi pass solar air heater with in-built thermal storage on deep-bed drying application, Journal of Food Engineering, 65(2004), 4, pp. 497-509.

2. Jain, D., Modeling the system performance of multi-tray crop drying using an inclined multi-pass solar air heater with in-built thermal storage, Journal of Food Engineering, 71(2005), 1, pp. 44-54.

3. Mittal, M.K., Varshney, L., Optimal thermo hydraulic performance of a wire mesh packed solar air heater, Solar Energy, 80(2006), pp. 1112- 1120.

4. El-Sebaii,A.A., et al., Year round performance of double pass solar air heater with packed bed, Energy Conversion and Management, 48(2007), 3, pp.990-1003

5. Prasad. S.B., et al., Investigation of heat transfer and friction characteristics of packed bed solar air heater using wire mesh as packing material, Solar Energy, 83(2019), 5, pp. 773-783.

6. Aldabbagh, L.B.Y., et al., Single and double pass solar air heaters with wire mesh as packing bed, Energy, 35(2010), 9, pp. 3783-3787

7. Omojaro, A.P., Aldabbagh, L.B.Y., Experimental performance of single and double pass solar air heater with fins and steel wire mesh as absorber, Applied Energy, 87(2010), 12, pp. 3759-3765.

8. Banout, J., et al., Using a double-pass solar drier for jerky drying, Energy Procedia, 30(2012), pp. 738-744

9. Banout, J., et al., Design and performance evaluation of a Double-pass solar drier for drying of red chilli (Capsicum annum L.), Solar Energy, 85(2011), 3, pp. 506-515

10. Krishnananth, S.S., Kalidasa Murugavel, K., Experimental study on double pass solar air heater with thermal energy storage, Journal of King Saud University - Engineering Sciences, 25(2013), 2, pp. 135-140.

11. Jadhav, D. B., et al., Solar Cabinet Drying of Bitter Gourd: Optimization of Pretreatments and Quality Evaluation, International Journal of Food Engineering, 6(2010), 4, pp. 1-18.

12. St. Paul Minnesota., AACC Approved Methods of American Association of Cereal Chemists., 10th edition, AACC, USA, 2000

13. Mohanraj, M., Chandrasekar, P., Drying of copra in a forced convection solar drier, Biosystems Engineering, 99(2008), 4, pp.604-607.

14. Montero, I., et al., Design, construction and performance testing of a solar dryer for agroindustrial by-products, Energy Conversion and Management, 51(2010), 7, pp. 1510-1521.

15. S.Vijayan, T.V.Arjunan and Anil Kumar (2016) "Mathematical modeling and performance analysis of thin layer drying of bitter gourd in sensible storage based indirect solar dryer" Innovative Food Science and Emerging Technologies, Volume 36, pp 59-67, 2016. 